Volume 8. No. 6, June 2020

International Journal of Emerging Trends in Engineering Research

Available Online at http://www.warse.org/IJETER/static/pdf/file/ijeter33862020.pdf

https://doi.org/10.30534/ijeter/2020/33862020

\title{
Preliminary study on the phase transformation of Ti-3Mo applying solid solution treatment for bone implant application
}

\author{
Kholqillah Ardhian Ilman ${ }^{1}$, Ngafwan ${ }^{2}$ \\ ${ }^{12}$ Department of Mechanical Engineering, Faculty of Engineering, Universitas Muhammadiyah Surakarta, \\ Surakarta, Indonesia \\ * Corresponding author: kholqillah.ardhian.i@ums.ac.id
}

\begin{abstract}
Purpose: This paper aims to find the phase transformation of Ti-3Mo at\% applying solid solution treatment.

Methodology: the Ti-3Mo specimens were produced by using arc melting furnace followed by homogenization in vacuum capsule at $1200^{\circ} \mathrm{C}$ for an hour. After that, the specimens were hot-rolled into $1.5 \mathrm{~mm}$ in thickness. Then, the specimens were solid solution treated at $1000^{\circ} \mathrm{C}$ for 10 minutes followed by rapid cooling (quenching). Phase and microstructure observation were conducted using XRD and optical microscope. TEM was also used in this study. Vickers hardness test was applied to confirm the homogeneity of the specimens.

Results: It was found that $\alpha$ "-martensite titanium with orthorhombic cell structure was the main phase of Ti-3Mo after solid solution treated followed by rapid cooling. Analysis of volume indicated that $\alpha$ "-martensite unit cell had similarity to $\beta$-phase titanium but $0.792 \%$ greater in volume. Further heat treatment needed to be applied in order to ensure the formation of $\beta$-phase in the specimen.

Applications: This study shows that the presence of molybdenum element in titanium alloys can prevent the formation of $\alpha$ hexagonal close packed (hcp) phase at room temperature.
\end{abstract}

Key words: Solid solution treatment, phase transformation, titanium

\section{INTRODUCTION}

The implant use has increased dramatically in recent years, accelerated by population aging in many countries, and the desire of people to keep at the same activity level and life quality. As a result, the demand for high-performance implantable biomaterials has also steadily increased. The variety and performance of the available biomaterials, and also the techniques for the manufacturing and assembling into an implantable device, have increased substantially, with a wide range of artificial, organic and hybrid materials available on the market [1]
Materials with bio-inert characteristics, typically based on Titanium, Cobalt and steel, are crucial for many load-bearing performances, where their corrosion resistance provides great long-term and consistent mechanical properties, with low long-term local or systemic toxicity to the host [2]. The materials have impressive mechanical properties, fatigue stress and fracture toughness, and have been applied as artificial joints in orthopaedics over the years [3].

Titanium is classified into one of the most commonly used biomaterials for orthopedic implant purposes [4]. The reason is due to its biocompatibility, resistance to corrosion, and lower Young's modulus than any other metallic biomaterials. On a specific study, [5] stated that the candidate of bio-metallic material with high chance for bone replacement would be Ti-alloys, with no neurotoxic factors, substances accused of inducing neurological diseases or allergic-effecting components.

Titanium also has excellent resistance to corrosion due to the presence of titanium dioxide as native film protecting the metal against further oxidation, making titanium is widely accepted as having high in vitro stability and corrosion resistance [6]. From the perspective of mechanical properties, titanium has promising future as bone implant. Niinomi [7] reported that there were conflicting preferences between patients and surgeons for metallic implants. Patient criteria specified that the implants must have low Young modulus, whereas the surgeons needed higher Young modulus to prevent springback during and after the surgery. And, Titanium alloys met the demands of patients and surgeons at the same time.

Commercially Pure (CP) Titanium has higher corrosion resistance and is widely considered to be the most biocompatible material due to the presence of inert oxide layer that forms spontaneously when exposed to an oxidizing media [8]. Previous study done by [9] showed that commercially pure titanium has poor wear resistance properties, resulting in the release of titanium particles that could damage the surrounding tissue. So that, in many biomedical applications, 
titanium comes in the form of alloys. Titanium alloys, mostly used for aviation purposes, gained attention from the biomedical industry, because of their compatibility, low elasticity modulus, and strong corrosion resistance [10]. Ti $6 \mathrm{Al}-4 \mathrm{~V}$ is one of the most frequently titanium alloy used for biomedical implant purposes [11]. The reason is the unchanged hardness property of $\mathrm{Ti}-6 \mathrm{Al}-4 \mathrm{~V}$ (after implantation in human body), making this alloy suitable to be applied as prosthetics cortical bone [12].

Vanadium is essentially used in titanium alloys as $\beta$ - phase stabilizer [13]. $\alpha \beta$ - phase and $\beta$ - phase titanium is widely used as biomaterials [11]. The presence of $\beta$ - phase titanium gives better biocompatibility when compared to the $\alpha$ - phase titanium only, because the value of Young's modulus is almost the same as that of cortical bone has, so it can minimize stress shielding phenomenon [14]. Stress shielding is an inappropriate load transfer phenomenon from artificial bone implants to the real bone [15]. This causes bone weakening and increases the probability of bone loss [16].

Regardless of the high rate of success of the Ti - 6Al - 4V transplantation process, the biocompatibility issue still comes into a serious problem (Calin et al., 2013). Studies on the biocompatibility aspect of $\mathrm{Ti}-6 \mathrm{Al}-4 \mathrm{~V}$ for biomedical implants were done by several researchers. Thompson \& Puleo [17] reported that sub-lethal concentrations of Ti-6Al-4V alloy ionic components can influence osteoblast expression and accumulation of mineralized substrate. They claimed that ions correlated with Ti-6Al-4V alloy may obstruct the normal stromal cells differentiation in the bone marrow and mature osteoblasts under in vitro situations. It was indicated that particles/ions released from implants could contribute to implant malfunction by impeding the natural process of bone deposition.

Ramirez \& Eastmond [18] who studied the effect of airborne vanadium particle on human body found that vanadium contributes to cancer development. Vanadium concentration was detected in the bone marrow of two persons with iliac joint implantation. Anemia, leukocytopenia and general vulnerability were recognized in a person body among of two [19]. Also, a study mentioned that the spread of vanadium ions from implant can provoke discoloration of the neighboring tissue or can trigger an inflammatory reaction that causes injury and can even contribute to osteolysis loosening [20]. A study conducted by Gomes et al [21]indicated that the ions released from $\mathrm{Ti}-6 \mathrm{Al}-4 \mathrm{~V}$ had possibility to damage human's DNA. Another study done by Lin et al [22] reported that vanadium ions could give long term health problem such as osteomalacia, alzheimer, and peripheral neuropathy. Okazaki \& Gotoh [23] also reported that vanadium had cytotoxicity characters which gave a harm effect to the human body. Although in reality, Vanadium is necessary element for human body but it turns into a detrimental in excessive number [24].

Molybdenum is considered to be an alternative $\beta$ - phase stabilizer due to nontoxic and nonallergenic for the human body [14]. Molybdenum is an element that has a lower harmful effect (toxicity level) compared to any other elements, such as $\mathrm{Co}, \mathrm{Ni}$, and $\mathrm{Cr}$. Addition of molybdenum element on titanium alloy was able to promote chance to be applied as bioimplant, especially from the perspective of mechanical properties [25]. It can enhance the ultimate tensile strength (UTS) but decrease the Young's modulus to avoid stress shielding phenomenon [26]. Chemically, the presence of molybdenum was able to improve the capability of corrosion resistance ([27].

Another investigation done by Abdelrahman et al [11]also revealed that the micro-content of molybdenum in Titanium alloys could inhibit the generation of corrosion. The corrosion product became attention regarding to the issue of biocompatibility.

The aim of this study is to observe the phase transformation of $\mathrm{Ti}-3 \mathrm{Mo}$ at $\%$ applying solid solution treatment at $1000 \mathrm{oC}$ for 10 minutes followed by rapid cooling (quenching). The result of this study will also be used as a preliminary study for taking the next step regarding the application of molybdenum as a $\beta$ - phase stabilizer that is safe for human body.

\section{METHODOLOGY}

\subsection{Specimen Preparation}

Ti-3Mo at\% specimens were made of elements with high level of purity. High grade pure titanium and molybdenum were purchased from Kojundo Chemical Laboratory Co., Ltd., Japan and The Nilaco Corporation, Japan, respectively. The specimens were produced using an electric arc-melting furnace with tungsten as the electrode in argon atmosphere environment. The specimen ingots were melted and inverted around 6 times to ensure the specimen homogenity. The mass of ingot was $10 \mathrm{gr}$, consisted of $9.416 \mathrm{gr}$ pure Titanium and 0,584 gr pure Molybdenum. After that, the ingot was homogenized in a vacuum capsule at $1200 \mathrm{oC}$ for an hour to promote uniform distribution of chemical content.

The homogenized Ti-3Mo specimens were hot-rolled at $800 \mathrm{oC}$ into $1.5 \mathrm{~mm}$ thick plates. This action resulted in nearly $85 \%$ reduction from its initial thickness. The hot-rolled specimens were cut into dimension $1 \mathrm{~cm} \times 1 \mathrm{~cm}$ square then solid solution treated at $1000 \mathrm{oC}$ for 10 minutes under argon atmosphere environment followed by rapid cooling (quenching) in ice water. Thick specimen with small area was expected to ensure perfect distribution of treatment temperature. 


\subsection{Phase and Microstructural Observations}

Phase observation of the specimens was operated by $\mathrm{Cu}-\mathrm{K} \alpha$ $\mathrm{X}$-ray diffractometry using diffractometer (Shimadzu, $\mathrm{XRD}-6100$ ) performing at $30 \mathrm{~mA}$ and $30 \mathrm{kV}$ in a range of $2 \theta$ between 30-80 degrees. For microstructural investigation, the specimens were mechanically polished using silicon carbide paper up to 1200 grit and polishing cloth with aluminium oxide (A12O3) suspension slurries, $0.3 \mathrm{~mm}$ then $0,05 \mathrm{~mm}$. After mechanically polished, the mirror-like surface of the specimens was etched for 15 second in a solution consists of $80 \% \mathrm{H} 2 \mathrm{O}$ (pure water), $15 \%$ HNO3 (nitric acid, technical-grade), and 5\% HF (hydrofluoric acid, technical-grade). The etched specimens then were examined using an optical microscope. Transmission Electron Microscope (TEM) was also used to investigate the microstructure of the specimens. Vickers hardness test was conducted using (Shimadzu HMV-FA) under load $5 \mathrm{~N}$ to confirm homogeneity of the specimens.

\section{RESULTS AND DISCUSSION}

The investigation of microstructure formation of Ti-3Mo alloys subjected to solid solution treatment at $1000^{\circ} \mathrm{C}$ for 10 minutes followed by rapid cooling has been carried out. The homogeneity of the specimens was confirmed by using vickers hardness test and it was carried out several times at different points on the specimens. Table 1 shows the vickers hardness numbers of the Ti-3Mo specimens at five different locations. It is seen that the highest value is $244.1 \mathrm{HV}$ while the lowest is $233.7 \mathrm{HV}$, with an average value is $238.4 \mathrm{HV}$. There is a small gap between the highest and the lowest hardness values, indicating that the homogeneity of the Ti-3Mo specimen is at a good level.

Table 1: Vickers hardness numbers of the Ti-3Mo specimens at five different locations.

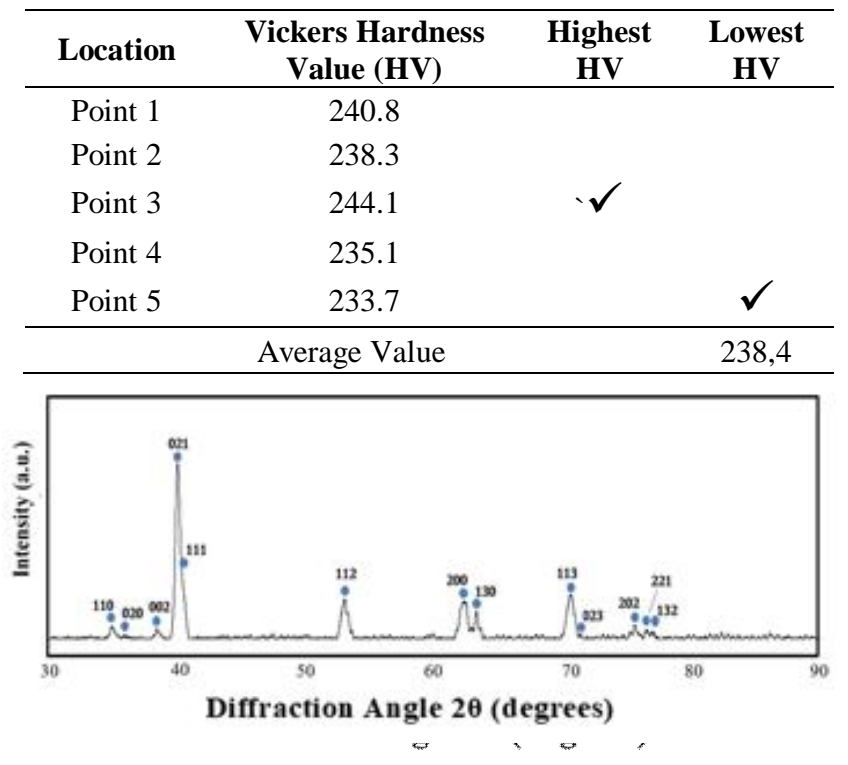

Figure 1: XRD graph of the Ti-3Mo specimen after being solid solution treated at $1000 \mathrm{oC}$ for 10 minutes.
Figure 1 depicts the XRD graph of the Ti-3Mo specimen after being solid solution treated at $1000^{\circ} \mathrm{C}$ for 10 minutes followed by rapid cooling (quenching). By comprehensive analysis of XRD peaks, it was found that the Ti-3Mo specimen is generally composed of $\alpha$ "-phases which have orthorhombic cell structures with lattice parameters are $a=301.2 \mathrm{pm}, b=$ $498.3 \mathrm{pm}$, and $c=465.8 \mathrm{pm}$, while bcc $\beta$-phase titanium has lattice parameter with $a=326.1 \mathrm{pm}$ and $b=c=461.2 \mathrm{pm}$ [28].

The presence of asymmetric parameter lattice is caused by stretching of crystal lattice from $\beta$-titanium phase (body-centered cubic) to $\alpha$-titanium phase (hexagonal close packed). Rapid cooling causes the molybdenum atoms do not have enough time to diffuse, resulting in distortion in the unit cell which results in an orthorhombic cell unit. Titanium with $\alpha$ "-phase becomes the main phase along with the addition of molybdenum to the titanium alloy after rapid cooling of the $\beta$-titanium phase [29].

The result of the microscope observation is shown in Figure 2. It depicts that the microstructure exists in the form of lamellar colonies with intersecting martensite laths. It is also seen that the size of the martensite lath is small with dense distribution. The small grain size is generated due to rapid cooling from $\beta$-titanium to $\alpha$-titanium. Further observation regarding to the appearance of the martensite $\alpha$ "-phases is performed by using Transmission Electron Microscope (TEM). Figure 3. shows TEM image with a low magnification of the Ti-3Mo specimen applying heat treatment followed by rapid cooling (quenching). As shown in Figure 3., the band-like structures (lath) are the $\alpha$ "-phases, indicated by white area (as pointed by arrow) [28].

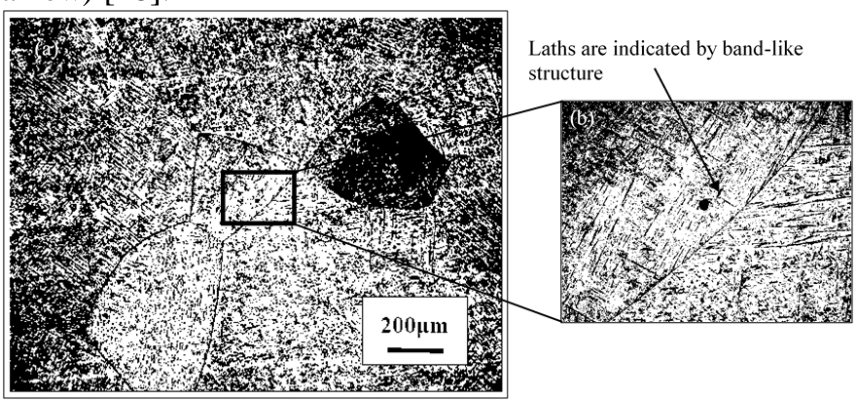

Figure 2:. Microscopic image of Ti-3Mo specimen. (a) 100X magnification; (b) 500X magnification.

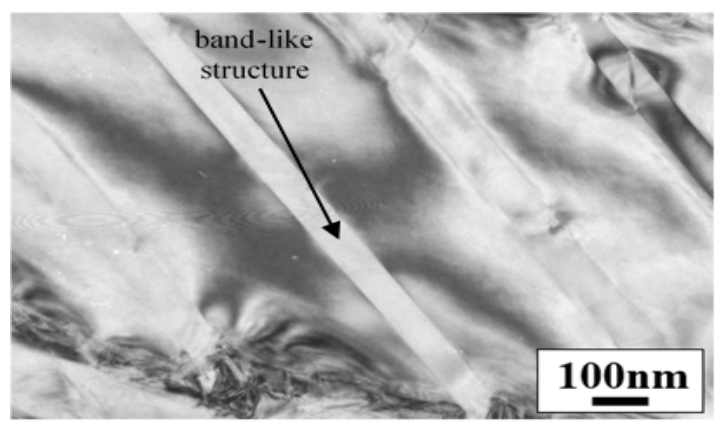

Figure 3. TEM image of the Ti-3Mo specimen. 
Kholqillah Ardhian Ilman et al., International Journal of Emerging Trends in Engineering Research, 8(6), June 2020, 2409 - 2413

Investigation on volume change of unit cells is used in this study to analyse the deformation phenomenon in unit cells that occurs on phase transformation from $\beta$-phase to $\alpha "$-phase martensite titanium. Analogically, the unit cells of the $\beta$-phase titanium and $\alpha$ "-phase martensite titanium have beam-like shape, with the lattice parameters a, b, and c can be analogous to be as length, height, and width, respectively. Figure 4 illustrates a simple analogy of the unit cell.

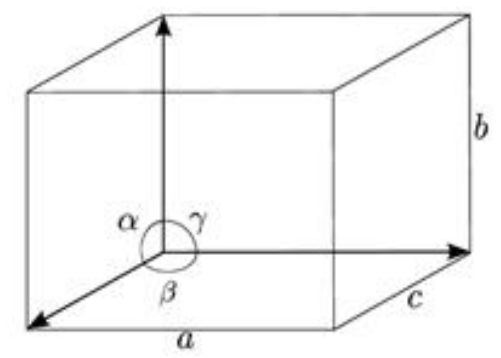

Figure 4: Simple analogy of $\beta$ and $\alpha^{\prime \prime}$-phase titanium unit cell. Each line intersects perpendicularly $\left(\alpha=\beta=\gamma=90^{\circ}\right)$.

Table 2: Lattice parameters and unit cell volume for each $\beta$-phase dan $\alpha$ "-phase titanium.

\begin{tabular}{|c|c|c|c|c|c|}
\hline \multirow{2}{*}{ Phase } & \multicolumn{3}{|c|}{ Lattice Parameter (pm) } & \multirow{2}{*}{$\begin{array}{l}\text { Volume of } \\
\text { Unit Cell } \\
\left(\mathrm{nm}^{3}\right)\end{array}$} & \multirow{2}{*}{$\begin{array}{c}\text { Expansion of } \\
\text { Volume }(\%) \\
\frac{V_{s}{ }^{\prime \prime}}{V_{\beta}} \\
\end{array}$} \\
\hline & $a$ & $b$ & $c$ & & \\
\hline$\alpha^{\prime \prime}$ & 301.2 & 498.3 & 465.8 & 0.06991 & \multirow{2}{*}{0.792} \\
\hline$\beta$ & 326.1 & 461.2 & 461.2 & 0.06936 & \\
\hline
\end{tabular}

Table 2 shows the lattice parameter values for $\beta$-phase and $\alpha$ "-phase in picometer (pm). By analogy as beam-like shape, it was found that the volume of the unit cells of $\beta$-phase and $\alpha$ "-phase were $0.06991 \mathrm{~nm}^{3}$ and $0.06936 \mathrm{~nm}^{3}$, respectively. There was an increase in volume by $0.792 \%$. The existence of this phenomenon shows that there has been a deformation in the unit cell when transitioning from $\beta$-phase to $\alpha$ "-martensite phase titanium. This indicates that the rapid cooling (quenching) of the $\beta$-phase titanium gives short time for the unit cell to fully transform into $\alpha$-phase titanium which has hexagonal close packed crystal system, causing little change in the volume of $\beta$-phase titanium which is called $\alpha$ "-phase martensite titanium.

Titanium alloys with $\alpha$ "-martensite as the main phase are not commonly used as bone implant. Study done by Niinomi [12] revealed that titanium-based bone implant were commonly composed of $\alpha, \alpha-\beta$, and $\beta$-phase titanium. Among these titanium types, $\beta$-phase was considered as the most suitable bone implant because of its properties, like elastic modulus and durability, were close enough to the real bone [30-32], around $30 \mathrm{GPa}$ [11]. According to these findings, it is concluded that further heat treatment is needed to obtain titanium alloy with a stable $\beta$-phase at room temperature.

\section{CONCLUSION}

Solid solution treatment followed by rapid cooling on Ti-3Mo at $\%$ has been carried out. The specimens were homogenized at $1200^{\circ} \mathrm{C}$ for an hour then solid solution treated at $1000^{\circ} \mathrm{C}$ until reach $\beta$-phase region for 10 minutes. Rapid cooling (quenching) was also applied to investigate the transformation behaviour of Ti-3Mo from $\beta$-phase to $\alpha$-phase titanium. X-Ray Diffraction test shows that $\alpha^{\prime \prime}$-martensite phase is the main phase of Ti-3Mo specimen. Presence of $\alpha$ " martensite phase is also confirmed by optical and transmission electron microscope.

From the optical microscope images, $\alpha^{\prime \prime}$ - martensite phase appears in band-like shape, some previous studies also call this appearance as "lath". The higher magnified image using transmission electron microscope reveals that $\alpha$ " - martensite phase titanium as white band structure. Analysis of volume is used to investigate the deformation phenomenon of Ti-3Mo unit cell. It is found that there is an increasing in unit cell volume by $0.792 \%$.

Increasing of volume happens when $\beta$-phase transform into $\alpha$ "-martensite phase titanium. Small amount of volume change indicates that rapid cooling after solid solution treatment gives short time for the unit cell to fully transform into $\alpha$-phase titanium (hexagonal close packed-crystal system), causing small deformation in the unit cell of $\beta$-phase which is called $\alpha$ "-phase martensite titanium. Due to the absence of $\beta$-phase at the end of this study, further treatment needs to be applied. Also, for future development, study on combination between bio-metal based material, such as titanium, and composite-based material[33] can be executed to promote good strenght-to-weight ratio of bone implant application.

\section{REFERENCES}

1. Ige OO, Umoru LE, Aribo S (2012) Natural Products: A Minefield of Biomaterials. ISRN Mater Sci 2012:1-20 https://doi.org/10.5402/2012/983062

2. Srivastav A (2011) An Overview of Metallic Biomaterials for Bone Support and Replacement. Biomed Eng Trends Mater Sci. https://doi.org/10.5772/13488

3. Saini M, Singh Y, Arora P, Arora V, Jain K (2015) Implant biomaterials: A comprehensive review. World J Clin Cases 3:52-57

4. Rack HJ, Qazi JI (2006) Titanium alloys for biomedical applications. Mater Sci Eng C 26:1269-1277

5. Abdel-Hady Gepreel M, Niinomi M (2013) Biocompatibility of Ti-alloys for long-term implantation. J Mech Behav Biomed Mater 20:407-415 https://doi.org/10.1016/j.jmbbm.2012.11.014

6. Liu X, Chu PK, Ding C (2004) Surface modification of titanium, titanium alloys, and related materials for 
biomedical applications. Mater Sci Eng R Reports 47:49-121

7. Niinomi M (2011) Low modulus titanium alloys for inhibiting bone atrophy. In: Biomater. Sci. Eng. pp 249-268

8. Elias CN, Lima JHC, Valiev R, Meyers MA (2008) Biomedical applications of titanium and its alloys. Biol Mater Sci 46-49

9. Sidambe AT (2014) Biocompatibility of advanced manufactured titanium implants-A review. Materials (Basel) 7:8168-8188 https://doi.org/10.3390/ma7128168

10. Wang W, Poh CK (2013) Titanium alloys in orthopaedics. In: Titan. Alloy. Adv. Prop. Control. pp $1-20$

11. Abdelrhman Y, Gepreel MA, Kobayashi S, Okano S, Okamoto T (2019) Biocompatibility of new low-cost ( $\alpha$ $+\beta)$-type Ti-Mo-Fe alloys for long-term implantation. Mater Sci Eng C ,99, 552-562.

12. Niinomi M (1998) Mechanical Properties of biomedical titanium alloys. Mater Sci Eng A A243:231-236

13. Jayaraj K, Pius A (2018) Biocompatible coatings for metallic biomaterials. In: Fundam. Biomater. Met. Elsevier, pp 323-354

14. Niinomi M (2017) Low-Modulus Ti Alloys Suitable for Rods in Spinal Fixation Devices. In: Interface Oral Heal. Sci. 2016. Springer, Singapore, pp 3-21 https://doi.org/10.1007/978-981-10-1560-1_1

15. Apostu D, Lucaciu O, Berce C, Lucaciu D, Cosma D (2018) Current methods of preventing aseptic loosening and improving osseointegration of titanium implants in cementless total hip arthroplasty: a review. J Int Med Res 46:2104-2119

16. Niinomi M, Nakai M (2011) Titanium-based biomaterials for preventing stress shielding between implant devices and bone. Int. J. Biomater. 2011:

17. Thompson GJ, Puleo DA (1996) Ti-6Al-4V ion solution inhibition of osteogenic cell phenotype as a function of differentiation timecourse in vitro. Biomaterials 17:1949-1954

18. Ramirez P, Eastmond DA, Laclette JP, Ostrosky-Wegman P (1997) Disruption of microtubule assembly and spindle formation as a mechanism for the induction of aneuploid cells by sodium arsenite and vanadium pentoxide. Mutat Res Mutat Res 386:291-298

19. Engh CJ, Moore K, Vinh T, Engh G (1997) Titanium prosthetic wear debris in remote bone marrow. A report of two cases. J Bone Jt Surg 79:1721-1725

20. Choubey A, Balasubramaniam R, Basu B (2004) Effect of replacement of $\mathrm{V}$ by $\mathrm{Nb}$ and $\mathrm{Fe}$ on the electrochemical and corrosion behavior of Ti-6Al-4V in simulated physiological environment. J Alloys Compd 381:288-294

https://doi.org/10.1016/j.jallcom.2004.03.096

21. Gomes CC, Moreira LM, Santos VJSV, Ramos AS, Lyon
JP, Soares CP, Santos F V. (2011) Assessment of the genetic risks of a metallic alloy used in medical implants. Genet Mol Biol 34:116-121

22. Lin C, Ju C, Ã JCL (2005) A Comparison of the Fatigue Behavior of Cast T -7 . 5Mo with c.p. Titanium , Ti 6Al $-4 \mathrm{~V}$ and $\mathrm{Ti}-13 \mathrm{Nb}-13 \mathrm{Zr}$ Alloys. Biomaterials 26:2899-2907

23. Okazaki Y, Gotoh E (2005) Comparison of metal release from various metallic biomaterials in vitro. Biomaterials 26:11-21

24. Browne M, Gregson PJ (1994) Surface modification of titanium alloy implants. Biomaterials 15:894-898

25. Sandu AV, Baltatu MS, Nabialek M, Savin A, Vizureanu $P$ (2019) Characterization and Mechanical Proprieties of New TiMo Alloys Used for Medical Applications. Materials (Basel) 12:2973

26. Kaur M, Singh K (2019) Review on titanium and titanium based alloys as biomaterials for orthopaedic applications. Mater Sci Eng C 102:844-862

https://doi.org/10.1016/j.msec.2019.04.064

27. Shapovalov O V., Shapovalova OM, Ivchenko TI (2006) Corrosion and mechanical properties of titanium alloyed with aluminum, iron, and molybdenum. Mater Sci 42:615-619

28. Mantani Y, Takemoto Y, Hida M, Sakakibara A, Tajima M (2004) Phase Transformation of _ $\alpha$ " Martensite Structure by Aging in Ti-8 mass\% Mo Alloy. Mater Trans 45:1629-1634

29. Davis R, Flower HM, West DRF (1979) The Decomposition of Ti-Mo Alloy Martensites by Nucleation and Growth and Spinodal Mechanisms. Acta Metall 27:1041-1052 https://doi.org/10.1016/0001-6160(79)90192-5

30. Wang K (1996) The use of titanium for medical applications in the USA. Mater Sci Eng A 213:134-137

31. Chandra S, Masood SH, Riza S (2020) Trends in Selective Laser Sintering in Biomedical Engineering. Internasional Journal of Emerging Trends in Engineering Research 8(1):54-59 https://doi.org/10.30534/ijeter/2020/10812020

32. Kumar ML, Krishnaiah D, Killari N (2015) Investigation on Mechanical Properties of CET Composite Materials. Internasional Journal of Emerging Trends in Engineering Research 3(Special Issue of NCTET 2015):516-519

33. Chandbadshah SBVJ, Arun K, Eswaraiah B (2015) Fabrication and Testing of Natural (Sisal) Fibre Reinforced Polymer Composites Material. Internasional Journal of Emerging Trends in Engineering Research 3(5):17-21 